ISSN: 2641-6794

\title{
Haiwan (Malay Version)
}

\author{
Uqbah Iqbal* \\ Managing Director, Malaysia \\ Received: 酮 November 23, 2018; Published: \\ *Corresponding author: Uqbah iqbal, Managing Director, Malaysia
}

\section{Opinion}

Translated by Fuzaini Sahar, through this book young children will be able to find out about the amazing world of stars. This book is one of the titles in the series of Young Science. Through careful research and interesting pictures, the series provides a start for children to discover and learn besides being the first encyclopedia for children. For every child, the world is full of new discoveries and knowledge. It is therefore important to have a knowledge book that allows even young children to discover and collect their own knowledge. Nature Science introduces a variety of children's acceptable topics. Each book in this series is produced by expert writers in addition to the help of educational advisors and experienced teachers so that all the information presented is simple and effective. Each book is complete and if collected, it can become a very important encyclopedia for students in the early years of schooling. Almost every page in this book has an interesting illustration. This book is written exclusively to stimulate children to find their own facts, thus opening the door to a world of fun knowledge. Wherever we are, there are always animals around us, whether a fly crawls on the leaves of the window, the spider builds its nest in the garden or the tiger who is watching its prey on the television. If readers like authors, readers would like to know what these animals are doing, how and why they do it. In this book the author introduces the main groups of animals and interesting facts about animals with the help of diagrams. The author has included a series of different types of animals that live in different world regions, the way of life and the nature of the animal. In accordance with the title, this book is about various types of animals. This is the starting point for recognizing the exciting animal world. There are different types of animals. Scientists divide animals into groups, tortoises are a kind of reptile, stickleback is a kind of fish, cricket is a kind of dengue, mice are a type of mammals, frogs are an amphibian and peacock are a kind of bird. All animals of the same group have the same properties. There are over a million kinds of animals. Each one is of different species. Scientists divide these species into two main groups. Animals with vertebrates are called vertebrates. While animals without vertebrae are called invertebrates. The main group is divided into small groups. Readers will find out about these groups in this book. There are extinct species of animals that are extinct because their shelter and food sources have been destroyed when humans cut down on forests, dried up marshes or polluting rivers and oceans.

Many animals whose size is too small to require a microscope to see it. Hundreds of these animals can fit into one pin head. Many microscopic animals live in water. This delicate paramesium does not look like an animal, but it moves and eats like other animals. These mesiens move in the water by sweeping the line of fine feathers. He also uses these feathers to put food into his mouth. All mammals also breastfeed their children. Mammals also have fur in the body. Some have thick fur to warm up during winter. Most mammals live on land and move on four feet. Some mammals hunt for other animals as food. The meat eaters are called carnivores. Others are herbivores and eat only herbs. Mammals can hear, see, and smell objects around them. Some mammals use fingers and nails to hold something. Some mammals live in large groups called groups. 


\section{(c) (i) This work is licensed under Creative}

To Submit Your Article Click Here: Submit Article

DOI: 10.32474/OAJESS.2018.01.000118

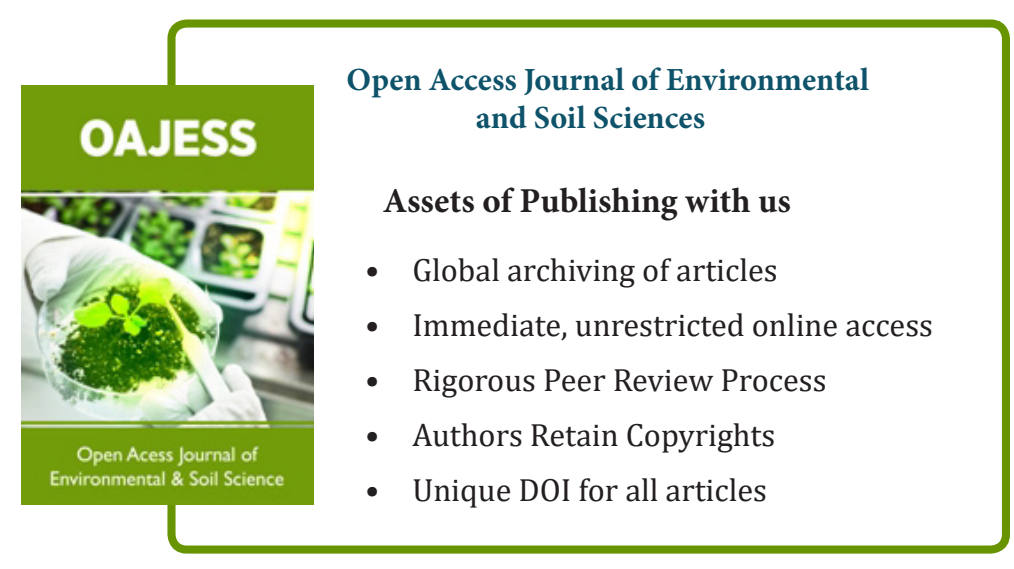

